\title{
The role of the Neotropics as a source of world tetrapod biodiversity
}

\author{
Andrea S. Meseguer ${ }^{1,2}$ (D) | Pierre-Olivier Antoine ${ }^{1}$ | Antoine Fouquet $^{3}$ | \\ Frédéric Delsuc $^{1}$ | Fabien L. Condamine ${ }^{1}$
}

${ }^{1}$ Institut des Sciences de l'Evolution de Montpellier, CNRS, Université de Montpellier, IRD, EPHE, Montpellier, France

${ }^{2}$ Real Jardín Botánico de Madrid (RJB), CSIC Madrid, Spain

${ }^{3}$ CNRS, Laboratoire Evolution et Diversité Biologique (EDB), UMR5174, Toulouse, France

\section{Correspondence}

Andrea S. Meseguer, Institut des Sciences de I'Evolution de Montpellier, CNRS, Université de Montpellier, IRD, EPHE, Montpellier,

France.

Email: asanchezmeseguer@gmail.com

\section{Funding information}

Agence Nationale de la Recherche, Grant/ Award Number: GAARAnti project (ANR-17CE31-0009) and Investissements d'Avenir CEBA (ANR-10-LABX-25-01)

Editor: Brian McGill

\begin{abstract}
Aim: The Neotropics currently host outstanding levels of species richness, with onethird of the global tetrapod species. The underlying causes of these extraordinary levels of biodiversity are a topic debated in evolutionary ecology, but the main processes at work remain elusive.

Location: Neotropics.

Time period: Cenozoic and Mesozoic.

Major taxa studied: Tetrapods.

Methods: Using global phylogenies for amphibians, birds, lepidosaurs and mammals, biogeographical and time-variable (trait-dependent and trait-independent) diversification models, we examined changes in speciation and extinction rates through time in the Neotropics in relationship to other areas of the world, and estimated the time of Neotropical colonizations.

Results: We found that from the origin of lepidosaurs and mammals until the Pliocene (the Miocene for birds), diversification rates within the Neotropics were lower than rates in other regions (i.e., turnover was high). Afterwards, extinction decreased relative to speciation, and Neotropical diversification outpaced diversification in other regions. Dispersal out of the Neotropics also increased after the Pliocene (the Miocene for birds), exceeding into-the-Neotropics migrations. For amphibians, diversification rates in the Neotropics have been higher than in other areas through time, and dispersal out of the Neotropics decreased in the Cenozoic.

Main conclusions: The common view that the Neotropics are an ancient source of world species diversity, with high in situ speciation, dispersal to other areas and low extinction, might be true only for amphibians. For mammals, birds and lepidosaurs, the Neotropics acted as a diversity sink from their origin until the Miocene-Pliocene (i.e., diversification rates were lower and turnover higher than in other areas). Only afterwards did the region turn into a diversity source. Our study highlights that models accounting for rates of diversification that vary through time could improve our capacity to assess evolutionary dynamics over long time-scales.
\end{abstract}

\section{KEYWORDS}

biogeography, dispersal, extinction, fossils, phylogeny, speciation, tetrapods 


\section{1 | INTRODUCTION}

For centuries, biologists and naturalists have been fascinated by the heterogeneous distribution of biological diversity on Earth, observing that species richness tends to be concentrated more in certain geographical regions than in others. Probably, the most striking distribution pattern is the increase in species richness observed towards the equator, or the latitudinal diversity gradient (Hillebrand, 2004). Within the equatorial belt, however, species diversity is not uniformly distributed, with species richness in the Neotropics being comparatively higher than in the Palaeotropics (tropical regions of Africa and the Indo-Australasian Archipelago) (Jenkins, Pimm, \& Joppa, 2013). The geographical configuration of the Neotropics has varied greatly through time (Hoorn et al., 2010), extending today from tropical Mexico to southern South America (Olson et al., 2001) and containing many of the recognized biodiversity hotspots in the world, such as the Caribbean, the Brazilian Cerrado and the richest of all, the tropical Andes (Mittermeier, Turner, Larsen, Brooks, \& Gascon, 2011). The underlying causes of the extraordinary levels of Neotropical biodiversity represent one of the most debated topics in evolutionary ecology (Gentry, 1982; Lagomarsino, Condamine, Antonelli, Mulch, \& Davis, 2016). Despite a wealth of proposed hypotheses, the main processes driving Neotropical diversity remain elusive (Antonelli \& Sanmartín, 2011; Hoorn et al., 2010).

The vast extent of the tropical biome in South America and its long climatic stability was first suggested to promote both the gradual accumulation of lineages and their long-term persistence in the region (Stebbins, 1974). This model received support from phylogenetic evidence showing a correlation between clade species richness and the amount of time for speciation in the region (Stephens $\&$ Wiens, 2003) and from studies finding no latitudinal differences in diversification rates (speciation minus extinction) (Antonelli et al., 2015; Jansson, Rodríguez-Castañeda, \& Harding, 2013). However, there is no general consensus, with other studies indicating a general increase of diversification rates towards the tropics in different lineages of amphibians (Pyron \& Wiens, 2013), mammals (Rolland, Condamine, Jiguet, \& Morlon, 2014; Weir \& Schluter, 2007), birds (Cardillo, Orme, \& Owens, 2005; Ricklefs, 2006; Weir \& Schluter, 2007), squamates (Pyron, 2014b) or plants (Jansson \& Davies, 2008), owing to the effect of high speciation, low extinction or both (Stebbins, 1974). Furthermore, a regional species pool also results from dispersal, with a prominent role of biogeographical processes in the biotic assembly (Jansson et al., 2013; Wiens \& Donoghue, 2004). Often, species diversity peaks in a clade area of origin, but geographical centres of extant diversity may not always coincide with ancestral origin, with some areas that favoured diversification historically and others that preserved this diversity (Becerra \& Venable, 2008).

To explain global-scale differences in species richness, two competing hypotheses could be formulated that capture the variations in speciation $(\lambda)$, extinction $(\mu)$ and dispersal $(d)$ between the Neotropics $(N)$ and other areas of the world, here referred to as "elsewhere" (E) (Antonelli et al., 2015; Becerra \& Venable, 2008; Figure 1):

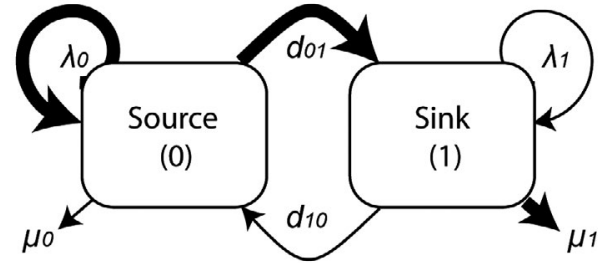

FIGURE 1 Schematic representation of the source-sink diversification hypotheses to explain the outstanding species richness in the Neotropics today. Species richness is the result of different speciation $(\lambda)$, extinction $(\mu)$ and dispersal $(d)$ rates in each area, with black arrows indicating the prevailing parameters. "Source" areas are characterized by high in situ diversification rates, as the product of high speciation and/or low extinction, accompanied by high rates of dispersal from the region to other areas. Conversely, "sink" areas are characterized by low diversification rates, as the product of low speciation and/or high extinction rates, with high dispersal rates from other regions increasing the net number of species

1. The scenario of Neotropics as a source of diversity states that diversity originated primarily in the Neotropics and that the region acted as a "pump" of species to other areas (Jablonski, Roy, \& Valentine, 2006). In this scenario, high in situ diversification rates $\left(r_{\mathrm{N}}>r_{\mathrm{E}}\right)$ are the product of high speciation and/or low extinction (i.e., Neotropics being both a cradle and/or a museum; Jablonski et al., 2006; Stebbins, 1974) and might be accompanied by high rates of dispersal from the Neotropics to other regions $\left(d_{\mathrm{NE}}>d_{\mathrm{EN}}\right)$. The species-pump model is probably the most supported model in the literature at different scales: when applied to the whole equatorial tropics (Rolland et al., 2014), to the Neotropics only (Pulido-Santacruz \& Weir, 2016) or even to regions within the Neotropics (e.g., whether Andean species contributed to Amazonian diversity or vice versa; Antonelli et al., 2018; Chazot et al., 2016; Fjeldså, Bowie, \& Rahbek, 2012). For flowering plants, a study found that the Neotropics acted as a pump of diversity but without significant differences in speciation and extinction rates between tropical and non-tropical angiosperms, and between the Neotropics and other tropical areas (Antonelli et al., 2015).

2. The scenario of Neotropics as a sink of diversity, conversely, suggests that geographical centres of extant diversity may not coincide with geographical centres of origin and that high dispersal rates from other regions into the Neotropics increased the net number of species in the region (i.e., the Neotropics acting as a "species attractor"; $d_{\mathrm{NE}}<d_{\mathrm{EN}}$ ) (Chazot et al., 2016; Pyron \& Wiens, 2013; Rolland, Condamine, Beeravolu, Jiguet, $\&$ Morlon, 2015). This scenario might occur under low speciation and/or high extinction rates in the Neotropics $\left(r_{N}<r_{E}\right)$. The "species attractor" effect has been documented for the Andes, where mountain uplift created new habitats and favoured the independent colonization of temperate groups (Chazot et al., 2016; Meseguer et al., 2018) and also for the tropical regions as a whole, with remarkable waves of dispersal "into the tropics" (Meseguer \& Condamine, 2020; Pyron \& Wiens, 2013; Rolland et al., 2015). In 
summary, the Neotropics "as a source" hypothesis emphasizes the role of in situ diversification, whereas the Neotropics "as a sink" puts forward the role of immigration to achieve the outstanding levels of diversity observed today, but these hypotheses are not mutually exclusive (Lagomarsino et al., 2016).

To date, however, most studies evaluating source-sink hypotheses have assumed that the global diversification dynamics persisted through evolutionary time, with the Neotropics (or the equatorial tropics) perceived as a prolonged source of world diversity. However, the processes shaping biodiversity might vary over space and time (Igea \& Tanentzap, 2019; Meseguer \& Condamine, 2020; Rolland et al., 2014), especially in relationship to the environmental and geological changes that occurred on Earth (e.g., landmass union and dislocation). Here, we took a macroevolutionary approach to investigate the origins and mechanisms underlying the extant Neotropical tetrapod biodiversity by analysing the global phylogenies of amphibians, birds, lepidosaurs (Squamata + Rhynchocephalia) and mammals. We applied models that simultaneously incorporated species traits and allowed diversification rates to vary at specific points in time to test the source and sink hypotheses.

\section{2 | MATERIALS AND METHODS}

\section{1 | Neotropical tetrapod diversity}

\subsection{1 | Molecular phylogenies}

We used the fossil-calibrated molecular phylogeny of Amphibia (Pyron $\&$ Wiens, 2013) that includes 3,126 species ( $40 \%$ of the described species; Table 1). For Lepidosauria, we relied on a time-calibrated phylogeny (Pyron, 2014b) including 4,162 species (40\% of known species). For Aves (birds), we used a global time-calibrated phylogeny (Jetz, Thomas, Joy, Hartmann, \& Mooers, 2012) including 6,670 species with genetic data ( $60 \%$ of extant bird diversity). Finally, for Mammalia, we used the Bininda-Emonds et al. (2007) supertree modified by Kuhn, Mooers, and Thomas (2011). This tree contains 5,020 species (77\% of the known diversity), some of which probably lack genetic data. Unfortunately, none of these mammal studies is clear regarding the exact number of species lacking genetic data or provides the identity of them. We are, therefore, constrained for pruning this tree. This tree places Afrotheria as the sister group of all remaining placentals (i.e., the Afrotheria rooting hypothesis). Given that there is uncertainty regarding the root of the placental phylogeny (Romiguier, Ranwez, Delsuc, Galtier, \& Douzery, 2013), we also evaluated an alternative rooting of this tree grouping Afrotheria and Xenarthra (the Atlantogenata rooting hypothesis).

\subsection{2 | Neotropical characterization}

Species were coded as distributed either in the Neotropics or elsewhere, with the Neotropics including the tropical terrestrial 
ecoregions of the Americas and the entire South American temperate zone, as delimited by the World Wide Fund for Nature (WWF) (Olson et al., 2001). We used the R package speciesgeocodeR v.1.0-4 (Töpel et al., 2017) to code species in or out of the Neotropics. The geographical distribution of species was first extracted from the Global Biodiversity Information Facility (https://www.gbif.org/) for all groups, but was complemented by the PanTHERIA database (https://omictools.com/pantheria-tool) for mammals and by BirdLife (http://www.birdlife.org) and eBird (http://ebird.org/content/ebird) for birds. We verified the resulting data sets visually for a random selection of species throughout the entire data set.

Fewer than $10 \%$ of the species of amphibians, birds, lepidosaurs and mammals are distributed in both Neotropical and Nearctic regions [e.g., only $1.3 \%$ (124 out of 9,292 world species) of lepidosaurs occur in both areas (Pyron, 2014b), or 3.1\% (210 out of 6,670 species) of birds in our data set]. Given that we could not consider widespread distributions (i.e., species occurring in more than one analytical unit) in our analyses (see section 2.2 below), we coded these species in the area covering most of their distribution or in elsewhere. This was a conservative approach because we wanted to test the effect of a Neotropical diversification. For seasonal migrant birds, breeding in northern latitudes but wintering in Neotropical regions, we coded these species in the breeding-season area; again, a conservative approach because most breeding areas of these birds are in the Nearctic (Pulido-Santacruz \& Weir, 2016). Recent studies also support that long-distance migrants originated from sedentary high-latitude ancestors (Winger, Barker, \& Ree, 2014).

\section{2 | Diversification analyses}

We applied a range of trait-dependent and trait-independent methods to test whether geographical traits, here a Neotropical or an elsewhere distribution, influence diversification. First, we used the binary state speciation and extinction (BiSSE) model (Maddison, Midford, \& Otto, 2007) implemented in the R package diversitree v.0.9-8 (FitzJohn, 2012). This model assumes a constant diversification rate through time for a given trait. To account for rate variation, we compared models where diversification rates were allowed to change at distinct time intervals (BiSSE.td). For the latter, we implemented one time shift (two time intervals) and tested different shift times at 3.5, 15, 34 and $66 \mathrm{Ma}$, which represent periods of environmental changes potentially affecting diversification: $3.5 \mathrm{Ma}$ corresponds to the final closure of the Panama Isthmus and the initiation of Northern Hemisphere glaciations (Zachos, Dickens, \& Zeebe, 2008); $15 \mathrm{Ma}$ coincides with the first land connections between South and Central Americas (Montes et al., 2015) and the middle Miocene climatic optimum (Zachos et al., 2008); $34 \mathrm{Ma}$ is the opening of the Drake passage (and collateral end of Antarctica-South America connection) with the onset of the Antarctic Circumpolar Current (Scher et al., 2015) and the GAARlandia bridge between North and South Americas (Iturralde-Vinent \& MacPhee, 1999); $66 \mathrm{Ma}$ is the Cretaceous-Palaeogene mass extinction (Longrich, Bhullar, \&
Gauthier, 2012). Implementing models with more than one time shift resulted in computationally (20 parameters) intractable analyses for phylogenies with thousands of species.

We designed a set of BiSSE and BiSSE.td models with increasing complexity, starting from a model with no difference in speciation, extinction and dispersal rates (three parameters) between areas and ending with the most complex model, with different rates for each area (six and 13 parameters in BiSSE and BiSSE.td, respectively; Supporting Information Tables S1 and S2). For each BiSSE and BiSSE. td model, we estimated maximum likelihood (ML) parameters and computed the corrected Akaike information criterion (AICc). Finally, the credibility intervals of the parameters were estimated in a Bayesian Markov chain Monte Carlo (MCMC) approach for the best model. Following the recommendations of FitzJohn (2012), we used an exponential prior of $1 /(2 r)$ and started the chain with the parameters obtained by maximum likelihood. We ran 10,000 MCMC steps and applied a burn-in of 1,000 steps. We accounted for incomplete taxon sampling in BiSSE and BiSSE.td by providing the sampling fraction of species at present having a given trait.

We could not use the geographical state change speciation and extinction (GeoSSE) model (Goldberg, Lancaster, \& Ree, 2011), which is appropriate when dealing with widespread species. For a character state to be considered a character in state speciation and extinction (SSE) models, it has to be represented in $>10 \%$ of the species, because the power of the trait-dependent models has been shown to be severely affected when high tip ratio bias is observed (Alves, Diniz-Filho, \& Villalobos, 2017; Davis, Midford, \& Maddison, 2013). Unfortunately, most species in our trees are endemic to one region (widespread species representing $<10 \%$ of our data set). The same limitations prevented us from using the multistate model and decomposing the "elsewhere" character into different continental units. In addition, BiSSE.td approaches have not yet been implemented for GeoSSE. Although the time-variable GeoSSE.t function allows diversification parameters to vary continuously through time (Rolland et al., 2014), time variation in this model is constant, such that parameters either increase or decrease all the way from the origin of the clade to the present. In this sense, this model is not adapted to infer whether the Neotropical region was a prolonged source of world diversity or the dynamic changed at specific time periods.

Issues associated with model adequacy and rejection in SSE approaches have recently been raised (Rabosky \& Goldberg, 2015). We explored the relationship between geographical distribution and diversification using the hidden state speciation and extinction (HiSSE) model in the R package HiSSE v.1.9.1 (Beaulieu \& O'Meara, 2016), which accounts for unmeasured factors ("hidden" states) that could impact diversification rates in addition to the trait of interest, a method that provides a solution to the issues detected with SSE models (Beaulieu \& O'Meara, 2016). We implemented a full HiSSE and two additional null models where diversification was allowed to vary but was not impacted by species distributions: a character-independent diversification model with two hidden states (CID-2) and a character-independent diversification model with four hidden states (CID-4). 
Finally, we used a time-variable (trait-independent) birth-death model to detect diversification rate shifts at specific branches of the tree as implemented in BAMM v.2.5 (Rabosky et al., 2013). We ran four independent MCMCs for 20million generations, sampling event data every 2,000 steps. Global incomplete sampling was accounted for by providing the proportion of species sampled in the tree. Appropriate priors were estimated with the setBAMMpriors command in the R package BAMMtools (Rabosky et al., 2014). The MCMC outputs were processed using effective sample sizes to check convergence, including the visualization of phylorate plots and rate-through-time plots for the history of the species currently distributed in the Neotropics and elsewhere.

\subsection{Colonizations into and out of the Neotropics}

We estimated when tetrapods colonized the Neotropics using two different approaches. First, the maximum-likelihood model "dispersal-extinction-cladogenesis" (DEC) was implemented in Lagrange (Ree \& Smith, 2008) and considered that all ranges composed of two areas could be ancestral states. Second, given that ancestral state estimations can be misleading when the potential impact of the trait on diversification is ignored (Maddison et al., 2007), we estimated the likeliest "Neotropical" and "elsewhere" states for internal nodes of a phylogeny using the function asr-bisse in diversitree and the bestfitting BiSSE model (ancestral reconstructions are not implemented for BiSSE.td in diversitree).

\section{3 | RESULTS}

\section{1 | Neotropical tetrapod diversity}

According to current distribution data, the Neotropics contain a substantial part of the world species diversity for tetrapods, with more than one-third of described species of amphibians, birds and lepidosaurs and $25 \%$ of mammals (average of $34.2 \%$; Table 1 ). The tetrapod time-calibrated phylogenies currently available include $24.2 \%$ of the described Neotropical species, on average.

\section{2 | Diversification analyses}

\subsection{1 | Time-constant diversification models}

The best-fitting time-constant BiSSE model for amphibians (Supporting Information Table S1) is the one with speciation and dispersal parameters differing between regions, while extinction remains equal $\left(\lambda_{N} \neq \lambda_{E} ; d_{N E} \neq d_{E N} ; \mu_{N}=\mu_{E}\right)$. In this model, speciation rates in the Neotropics are higher than those in the rest of the world $\left(\lambda_{N}=0.078\right.$ versus $\lambda_{E}=0.062$ ), and dispersal rates out of the Neotropics are higher than into the Neotropics $\left(d_{\mathrm{EN}}\right.$ $=0.0$ versus $d_{\mathrm{NE}}=0.001$ ). The best-fitting BiSSE model for lepidosaurs has speciation and extinction rates differing between regions, while dispersal rates are $\operatorname{similar}\left(\lambda_{\mathrm{N}} \neq \lambda_{\mathrm{E}} ; \mu_{\mathrm{N}} \neq \mu_{\mathrm{E}} ; d_{\mathrm{NE}}=\right.$ $d_{\mathrm{EN}}$; Supporting Information Table S1). Both speciation and extinction rates are higher in the Neotropics $\left(\lambda_{E}=0.064\right.$ versus $\lambda_{N}=$ $0.169, \mu_{E}=0.0$ versus $\left.\mu_{N}=0.101\right)$. For birds, the best-fitting BiSSE model is the one with speciation and dispersal parameters differing between regions, while extinction remains equal $\left(\lambda_{N} \neq \lambda_{E}\right.$; $\left.d_{\mathrm{NE}} \neq d_{\mathrm{EN}} ; \mu_{\mathrm{N}}=\mu_{\mathrm{E}}\right)$. Speciation rates in the Neotropics $\left(\lambda_{\mathrm{N}}=0.161\right)$ are higher than in the rest of the world $\left(\lambda_{E}=0.092\right)$, and dispersal rates out of the Neotropics $\left(d_{\mathrm{NE}}=0.0193\right)$ are higher than into the Neotropics ( $d_{\mathrm{EN}}=0.0057$ ). For mammals, the best-fitting BiSSE model is the one with all parameters differing between regions (Supporting Information Table S1). In this model, speciation rates in the Neotropics are higher than in the rest of the world $\left(\lambda_{N}=0.152\right.$ versus $\left.\lambda_{E}=0.117\right)$, as are extinction rates $\left(\mu_{E}=0.011\right.$ versus $\mu_{N}=0.094$ ). Dispersal rates from the Neotropics to other regions are higher than the other way around $\left(d_{\mathrm{NE}}=0.010\right.$ versus $\left.d_{\mathrm{EN}}=0.003\right)$. Very similar results are obtained with the two alternative rooting schemes of the placental mammal phylogeny tested (Supporting Information Table S1). Bayesian MCMC analyses of the best-fitting models for each group are portrayed in the Supporting Information (Figures S1-S4).

Full-HiSSE analyses receive higher support than BiSSE analyses for all the groups, although unfortunately, time-variable models are not yet implemented for this model, and comparisons could not be make with BiSSE.td results, only with BiSSE (Table 2; Supporting Information Figures S5-S8).

TAB LE 2 Comparison of best BiSSE, HiSSE and BiSSE.td models for the global phylogeny of Aves, Amphibia, Lepidosauria and Mammalia based on the corrected Akaike information criterion

\begin{tabular}{llllll}
\hline Clade & CID-2 & HiSSE & CID-4 & BiSSE.td & BiSSE \\
\hline Amphibia & $34,788.099$ & $25,941.598$ & $25,957.21$ & $26,437.48$ & $36,577.66$ \\
\hline Lepidosauria & $34,788.099$ & $33,599.055$ & $33,579.072$ & $34,691.29$ \\
\hline Aves & $45,967.449$ & $44,946.52$ & $45,393.155$ & $46,671.34$ & $46,935.395$ \\
\hline Mammalia (Afrotheria rooting) & $32,907.591$ & $32,583.092$ & $32,813.524$ & $34,333.23$ \\
\hline Mammalia (Atlantogenata rooting) & $33,964.051$ & $33,534.642$ & $33,785.534$ & $34,348.42$ & $34,598.59$ \\
\hline
\end{tabular}

Note.: The best-fitting model among all five tested models is indicated in bold for each clade.

BiSSE, binnary state speciation and extinction model; BiSSE.td, time-dependent Binnary State Speciation and Extinction model; CID-2, character independent model; HiSSE, hidden state speciation and extinction. 


\subsection{2 | Time-variable diversification rate models}

In all cases, allowing diversification rates to change at a specific point in time increases the fit of the model in comparison to constant-time BiSSE models (Table 3). The best-fitting BiSSE.td model for amphibians includes a rate shift at $66 \mathrm{Ma}(\mathrm{AICc}=26,437.5$; Table 3 ) and all diversification parameters differing between regions (Supporting Information Table S2). Net diversification rates in the Neotropics are higher than in other regions through time (both speciation and extinction; Supporting Information Figure S9), and diversification outside the Neotropics approached zero before $66 \mathrm{Ma}$ (Figure 2). Dispersal rates out of the Neotropics exceed dispersal rates into the Neotropics in all periods. Nonetheless, after the rate shift at $66 \mathrm{Ma}$, dispersal rates decrease globally, whereas net diversification rates increase globally. This is attributable to a decrease in speciation and a larger decrease in extinction in the Neotropics, whereas in other regions an increase in speciation and a decrease in extinction are inferred.

The best-fitting BiSSE.td model for lepidosaurs has a rate shift at 3.5 $\mathrm{Ma}$ ( $\mathrm{AICc}=34,736.8$ ), with speciation and dispersal rates differing between regions (Figure 2; Supporting Information Figure S10; Table S2). During the first time interval (from the origin to $3.5 \mathrm{Ma}$ ), diversification rates in the Neotropics are lower than in the rest of the world owing to a relatively higher extinction in the region. After 3.5 $\mathrm{Ma}$, extinction in the Neotropics decreases, and diversification rates in the Neotropics exceed diversification rates elsewhere.

For birds, the best-fitting BiSSE.td model is the one with a rate shift at $15 \mathrm{Ma}(\mathrm{AICc}=46,671.34)$ and speciation and transition parameters differing between regions (Figure 2; Supporting Information Table S2). Diversification rate estimates are lower in the Neotropics before $15 \mathrm{Ma}$, but after this period diversification increases in the Neotropics owing to reductions in Neotropical extinction rates (Supporting Information Figure S11). Dispersal rates are lower out of the Neotropical region until $15 \mathrm{Ma}$; afterwards, migrations out of the Neotropics exceed dispersals into the Neotropics.

For mammals, the best-fitting BiSSE.td model is the one with a rate shift at $3.5 \mathrm{Ma}(\mathrm{AICc}=34,333.2)$ and all diversification parameters differing between regions (Supporting Information
Table S2). The same results are obtained with the two alternative rooting schemes of the placental phylogeny (Supporting Information Table S2). Before the rate shift at 3.5 Ma, diversification rates in the Neotropics are lower than in other regions, and speciation and extinction are higher in the Neotropics, suggesting high turnover (Figure 2; Supporting Information Figure S12). After the rate shift, extinction is reduced worldwide, and diversification rates in the Neotropics increase relative to diversification elsewhere. Dispersal rates out of the Neotropics exceed migrations into the Neotropics in both periods. After the rate shift, however, dispersal rates increase out of the Neotropics relative to the former period.

The BAMM analyses reveal multiple increases in diversification rates in all trees: 20 for amphibians, 46 for birds, 22 for lepidosaurs and 40 for mammals, most of them concentrated in the last $50 \mathrm{Myr}$. However, inspection of branch-specific rates in light of ancestral-range estimations does not reveal any clear geographical pattern in the phylogenetic location of diversification shifts (Supporting Information Figures S13-S16). Diversification shifts are not clearly associated with the colonization of Neotropical regions. Ratethrough-time plots depict an initial phase of similar diversification rates for amphibians distributed in the Neotropics and elsewhere, followed by a disproportionate increase c. $66 \mathrm{Ma}$ for Neotropical species (Figure 3). Rates are slightly higher for Neotropical than elsewhere species of lepidosaurs through time, with the difference increasing in the last few million years. For birds, there are slightly higher diversification rates outside the Neotropics until the Neogene, when Neotropical diversification outpaces elsewhere diversification. Finally, for mammals, diversification is relatively constant and higher in the Neotropics through time until the recent past, when diversification increases in both regions.

\subsection{Colonizations into and out of the Neotropics}

Under both the DEC and BiSSE models, amphibians, birds and lepidosaurs are estimated to be distributed outside the Neotropics at their origin with high probability (Supporting Information Figures S13-S15). Entry to the Neotropics is estimated around the

TAB LE 3 Comparison of best BiSSE and BiSSE.td models for the global phylogeny of Aves, Amphibia, Lepidosauria and Mammalia based on the corrected Akaike information criterion

\begin{tabular}{|c|c|c|c|c|c|c|}
\hline \multirow[b]{2}{*}{ Clade } & \multirow[b]{2}{*}{ BiSSE } & \multicolumn{4}{|l|}{ BiSSE.td } & \multirow[b]{2}{*}{$\Delta \mathrm{AICc}$} \\
\hline & & $3.5 \mathrm{Ma}$ & $15 \mathrm{Ma}$ & $34 \mathrm{Ma}$ & $66 \mathrm{Ma}$ & \\
\hline Amphibia & $26,577.66$ & $26,529.48$ & $26,509.13$ & $26,480.94$ & $26,437.48$ & 43.46 \\
\hline Lepidosauria & $34,804.48$ & $34,691.29$ & $34,708.19$ & $34,751.14$ & $34,769.05$ & 16.90 \\
\hline Aves & $46,935.39$ & $46,705.492$ & $46,671.34$ & $46,838.445$ & - & 34.15 \\
\hline Mammalia (Afrotheria rooting) & $34,598.59$ & $34,333.23$ & $34,432.45$ & $34,501.43$ & $34,423.40$ & 90.17 \\
\hline $\begin{array}{l}\text { Mammalia (Atlantogenata } \\
\text { rooting) }\end{array}$ & $34,602.08$ & $34,348.42$ & $34,434.11$ & $34,503.22$ & $34,464.30$ & 85.69 \\
\hline
\end{tabular}

Note: The best-fitting model among all five tested models is indicated in bold for each clade. The four tested BiSSE.td models correspond to models allowing a single rate shift occurring at different time periods $(3.5,15,34$ and $66 \mathrm{Ma}) . \Delta \mathrm{AICc}=$ difference in the corrected Akaike information criterion between the best model and the next most-supported model. 

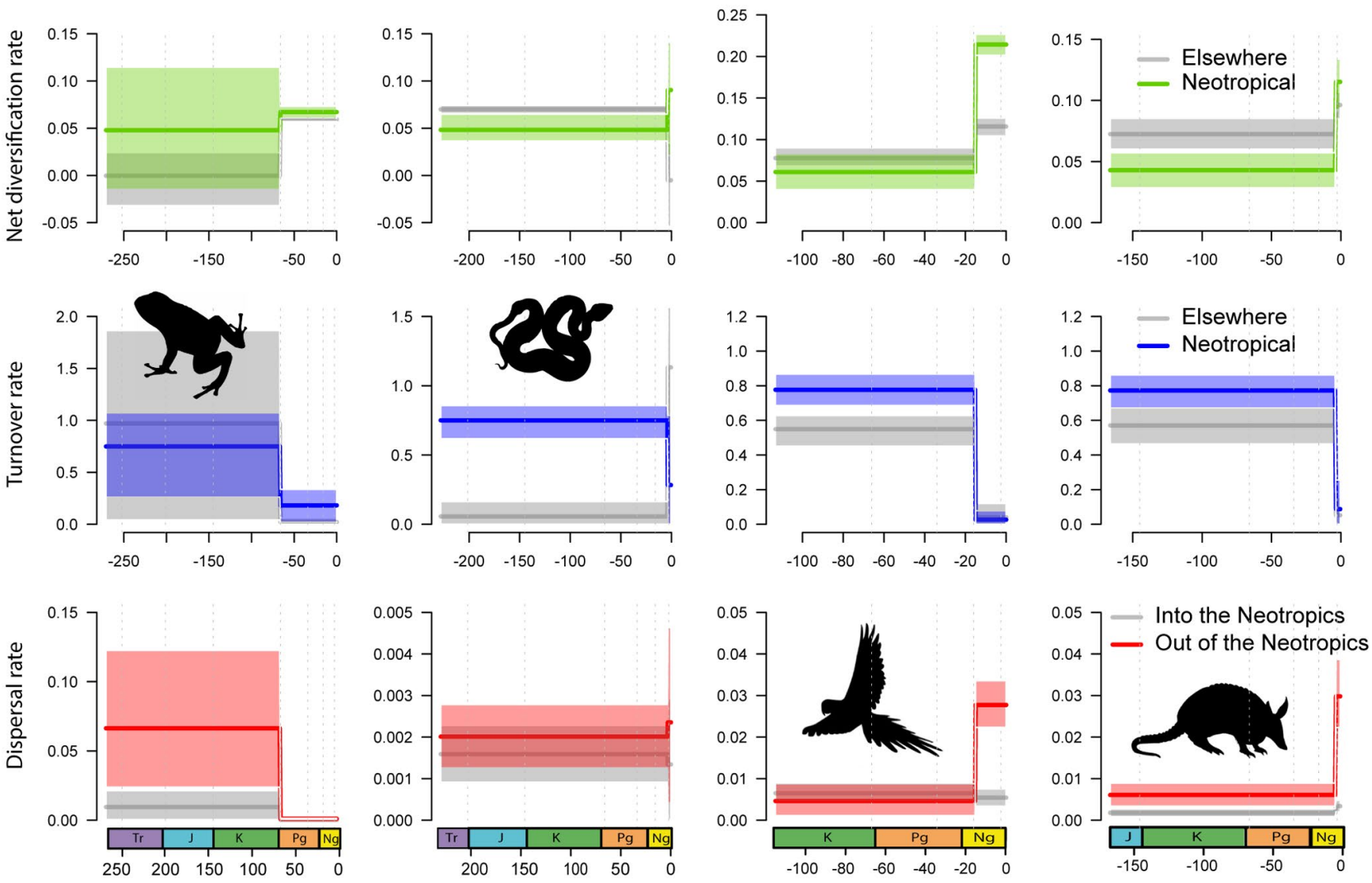

Time (Ma)

FIGURE 2 Diversification patterns inferred with the time-variable BiSSE.td model for Amphibia, Lepidosauria, Aves and Mammalia (top to bottom). Bayesian posterior distributions for net diversification ( $r=$ speciation minus extinction), turnover ( $a=$ extinction/speciation) and dispersal rates, estimated using Markov chain Monte Carlo analyses for species living in the Neotropics and in other parts of the world ("elsewhere") before and after the inferred time shift in diversification at $66 \mathrm{Ma}$ for amphibians, $15 \mathrm{Ma}$ for birds and $3.5 \mathrm{Ma}$ for lepidosaurs and mammals (Table 3). Shaded areas represent the $95 \%$ credibility interval of each estimated parameter and solid lines mean values [Colour figure can be viewed at wileyonlinelibrary.com]
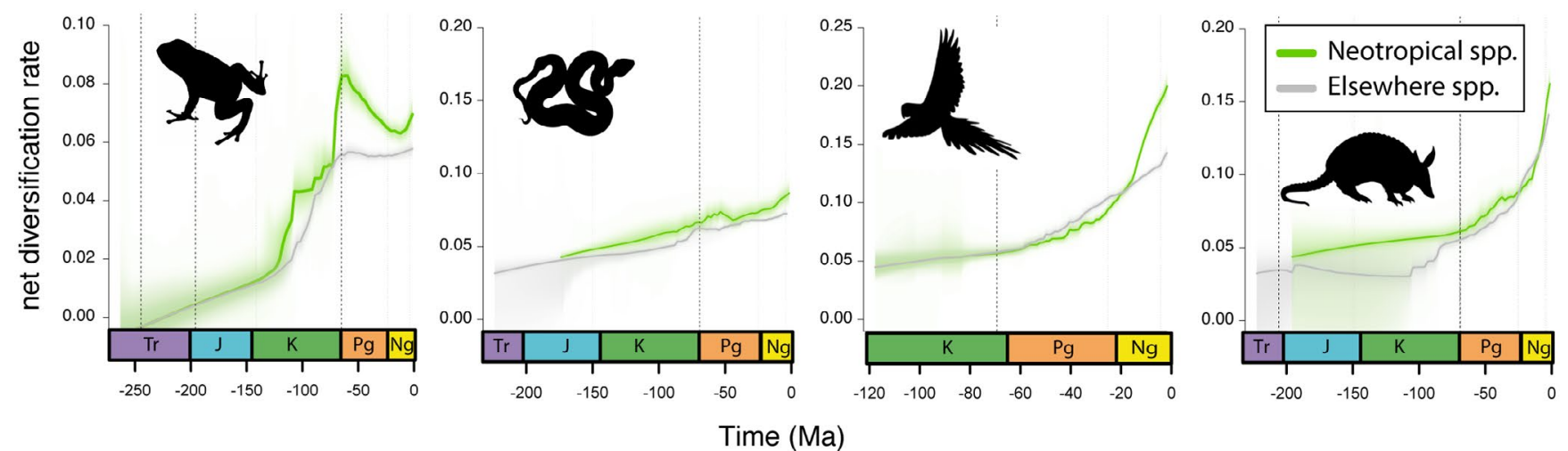

Time (Ma)

FIGURE 3 Net diversification rate-through-time plots estimated by BAMM for current species of Amphibia, Lepidosauria, Aves and Mammalia distributed in the Neotropics and elsewhere. Shading represents confidence intervals. Time is expressed as millions of years ago [Colour figure can be viewed at wileyonlinelibrary.com]

Late Cretaceous for amphibians and lepidosaurs. For birds, it is estimated in the Eocene with BiSSE and the Late Cretaceous with DEC (Figure 4). There was not a single colonization in the Neotropics, but multiple immigrations. For mammals, results are incongruent between the two methods. The ancestors are reconstructed in the Neotropics $>150 \mathrm{Ma}$ with BiSSE, from where multiple clades colonized other regions after $60 \mathrm{Ma}$ (Supporting Information Figure $\mathrm{S} 16)$, whereas in DEC the ancestors are estimated to be distributed 
outside the Neotropics at their origin, with a Neotropical colonization during the Palaeocene.

\section{4 | DISCUSSION}

The Neotropics host outstanding levels of species richness, with nearly $43 \%$ of the world amphibians, $38 \%$ of birds, $34 \%$ of lizards and snakes and $25 \%$ of mammals distributed in the region today (Table 1). It is generally considered that the Neotropics and other tropical regions represent sources of global diversity as a result of the combination of different factors, including time (most groups originated in the tropics and had more time to diversify; Stephens \& Wiens, 2003) or climatic stability (Stebbins, 1974). Higher rates of species diversification in tropical climates than in temperate climates, partly attributable to lower extinction, are also often proposed to explain this pattern for mammals (Rolland et al., 2014), lepidosaurs (Pyron, 2014b), amphibians (Pyron \& Wiens, 2013) and birds (Cardillo et al., 2005; Pulido-Santacruz \& Weir, 2016; Ricklefs, 2006; Weir \& Schluter, 2007). Most of these studies relied on similar SSE models to the ones used here, but assumed that diversification remained constant through time. In our study, however, models accounting for varying diversification rates outperformed time-constant models (Table 3), suggesting that global biodiversity dynamics between the Neotropics and other regions changed through time.

Here, we asked whether the Neotropics have acted as a prolonged source of world diversity. This scenario seems to apply only for Amphibia. Diversification rates of amphibians in the Neotropics were higher than elsewhere through time, in agreement with previous studies focusing on amphibians in the whole tropical belt
(Pyron \& Wiens, 2013; Figures 2 and 3). Dispersal rates out of the Neotropics also surpassed dispersal into the Neotropics. This agrees with a prolonged "source of diversity" scenario and with the "out of the tropics" model of Jablonski et al. (2006). The fossil record indicates that amphibian crown representatives might have been distributed in Western Gondwana (Neotropics) since the Middle Jurassic (182.7-168.3 Ma; Table 4; Supporting Information Appendix S1, data sources), which is also suggested by some phylogenetic evidence (Pyron, 2014a; Rolland \& Condamine, 2019). However, our BiSSE and DEC reconstructions support different independent colonizations of Western Gondwana in the late Cretaceous (c. 100 Ma; Figure 4), as in other studies (Feng et al., 2017; Pyron \& Wiens, 2013).

Additionally, our BiSSE.td and BAMM results might suggest that amphibian diversification increased through time in all regions, with diversification intensifying after $66 \mathrm{Ma}$ (i.e., during the Cenozoic; Figures 2 and 3). Arboreal frog species represent $82 \%$ of current amphibian diversity and originated around the Cretaceous-Palaeogene (K-Pg) transition. New ecological opportunities reset by the $\mathrm{K}-\mathrm{Pg}$ extinction associated with the turnover of other amniotes and the rise of angiosperm-dominated forests could have contributed to increase diversification (Feng et al., 2017; Roelants et al., 2007). Unfortunately, we cannot confirm this hypothesis, because our analyses are not the most appropriate to address this question; BiSSE. td is looking for tree-wide shifts of diversification that are punctual while assuming constant diversification within each specific time period. Hence, we can determine that diversification dynamics differed before and after $66 \mathrm{Ma}$, but we cannot discard the possibility that diversification increased/decreased within each time bin. In fact, diversification of Neotropical amphibians during the Cenozoic decreased as suggested by BAMM (Figure 3). On the contrary, BAMM
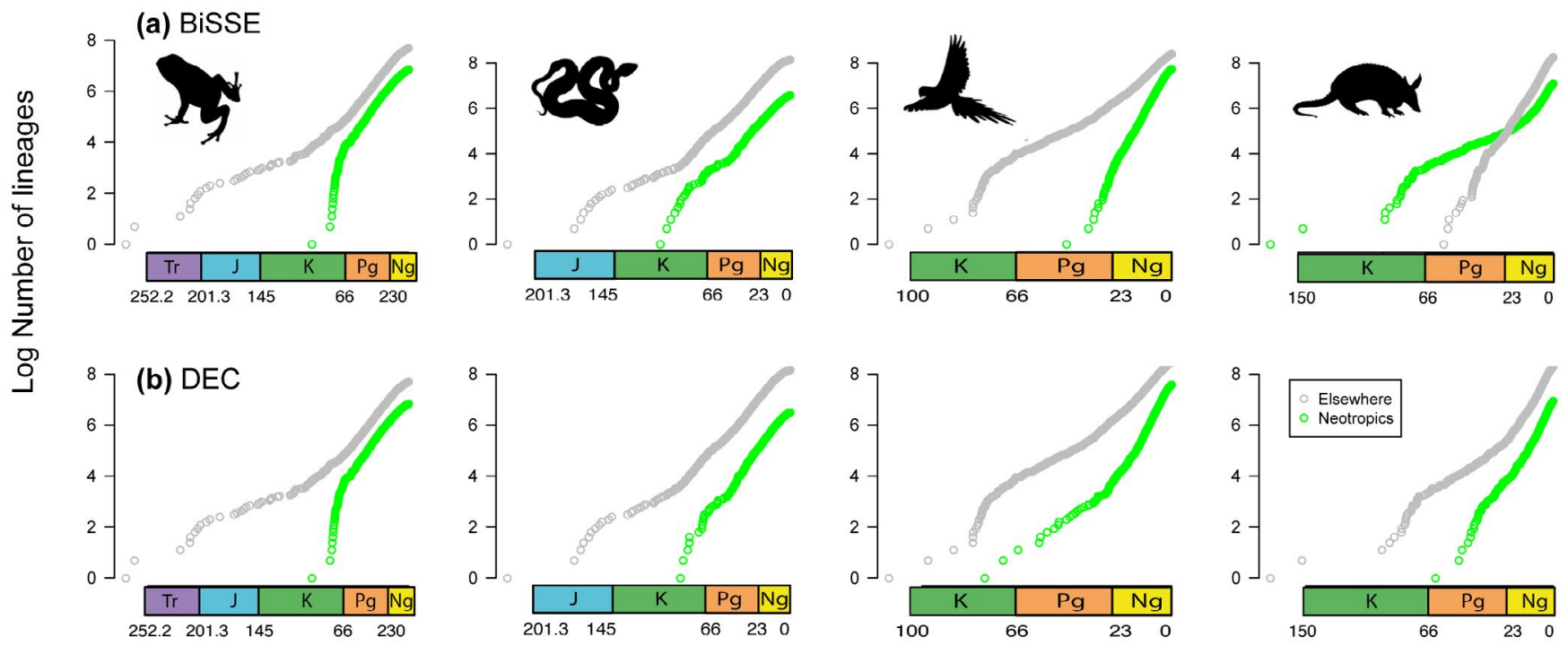

Time (Ma)

FIGURE 4 Lineage-through-time plots for Neotropical and elsewhere species as reconstructed across the phylogenetic trees of Amphibia, Lepidosauria, Aves and Mammalia using (a) the ancestral reconstruction algorithms in BiSSE under the best-fitting model (Table S1) and (b) the dispersal-extinction-cladogenesis (DEC) model. Time is expressed as millions of years ago [Colour figure can be viewed at wileyonlinelibrary.com] 


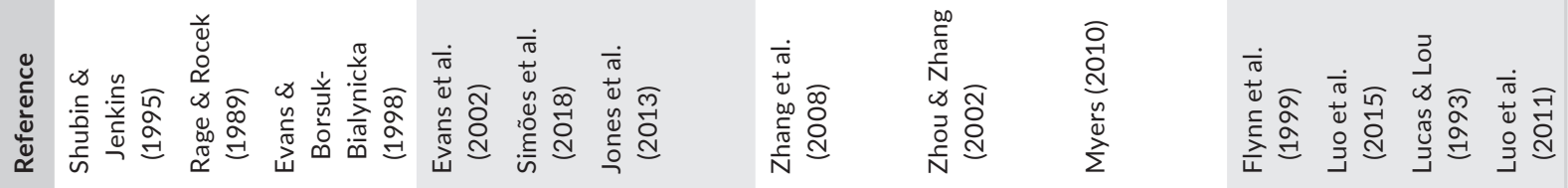

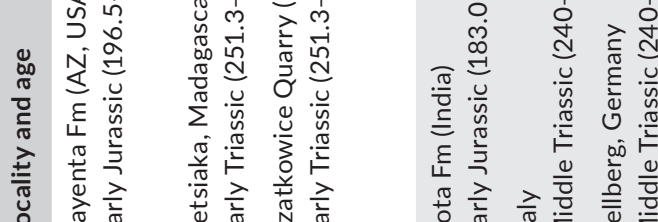

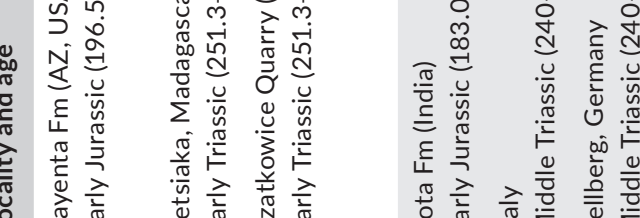

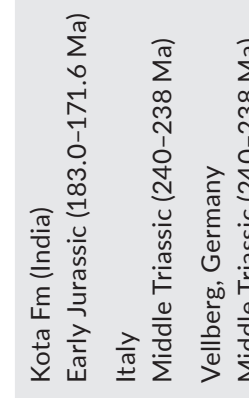

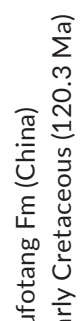

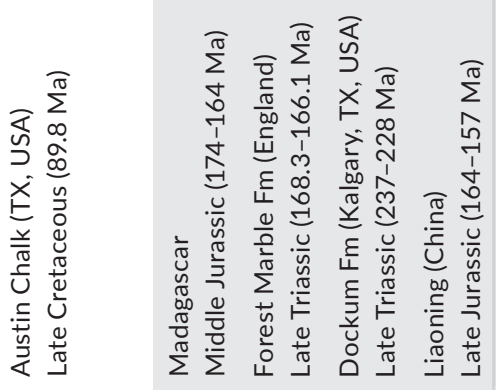

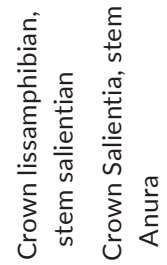

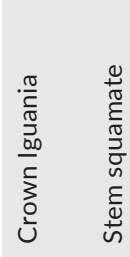

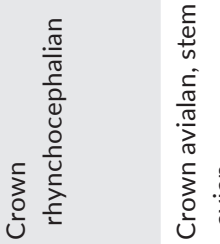

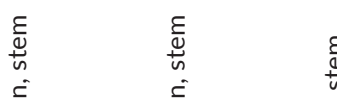

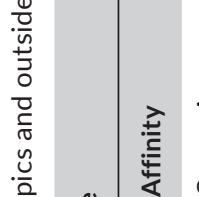

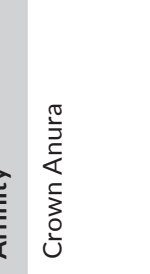

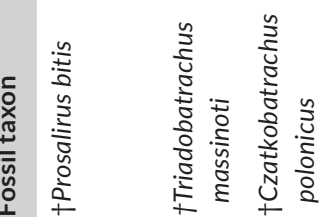

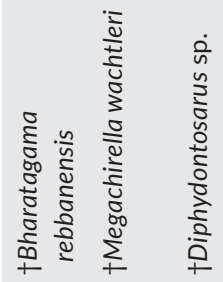

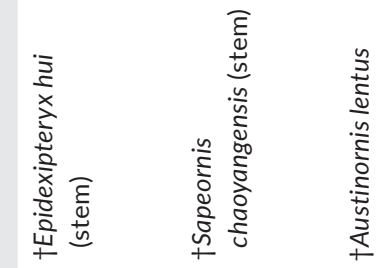

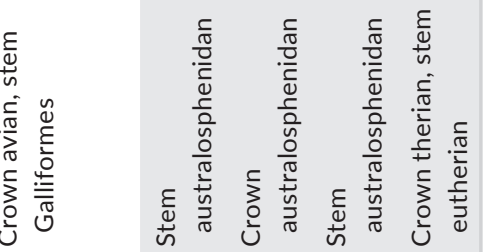

함

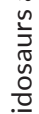

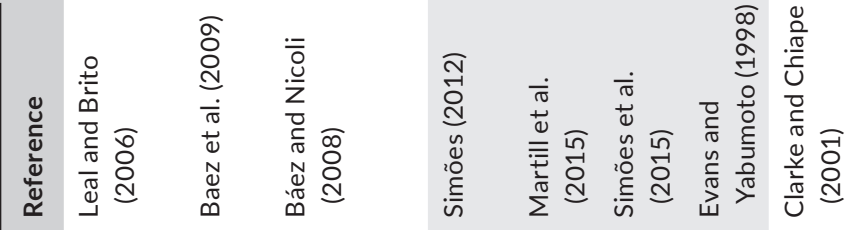

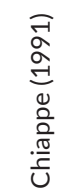

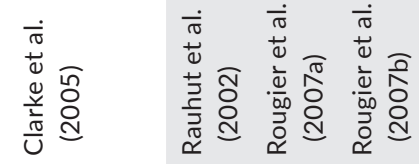

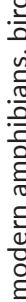

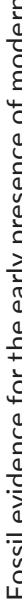

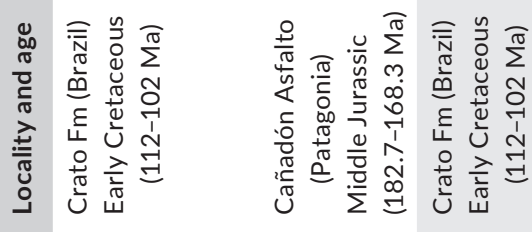

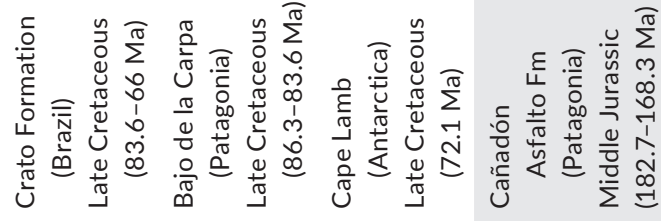

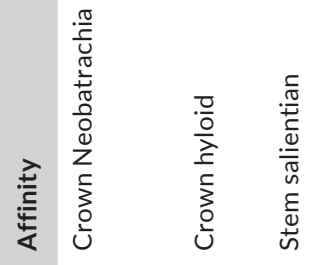

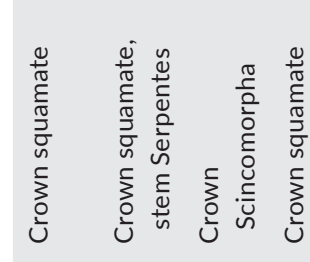

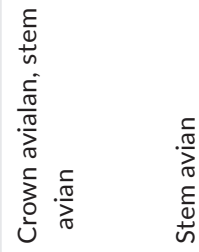

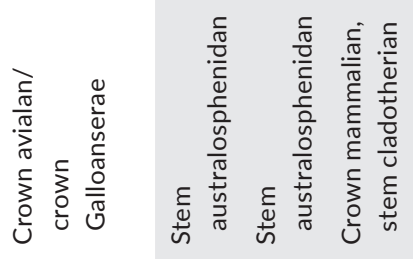

$\stackrel{\oplus}{\rightleftharpoons}$

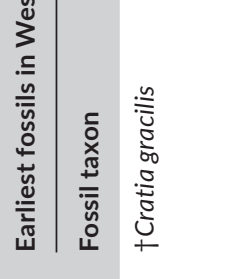

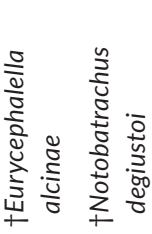

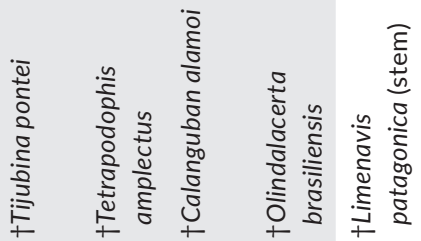

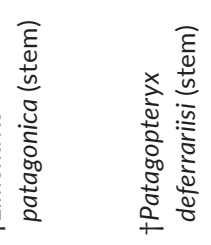
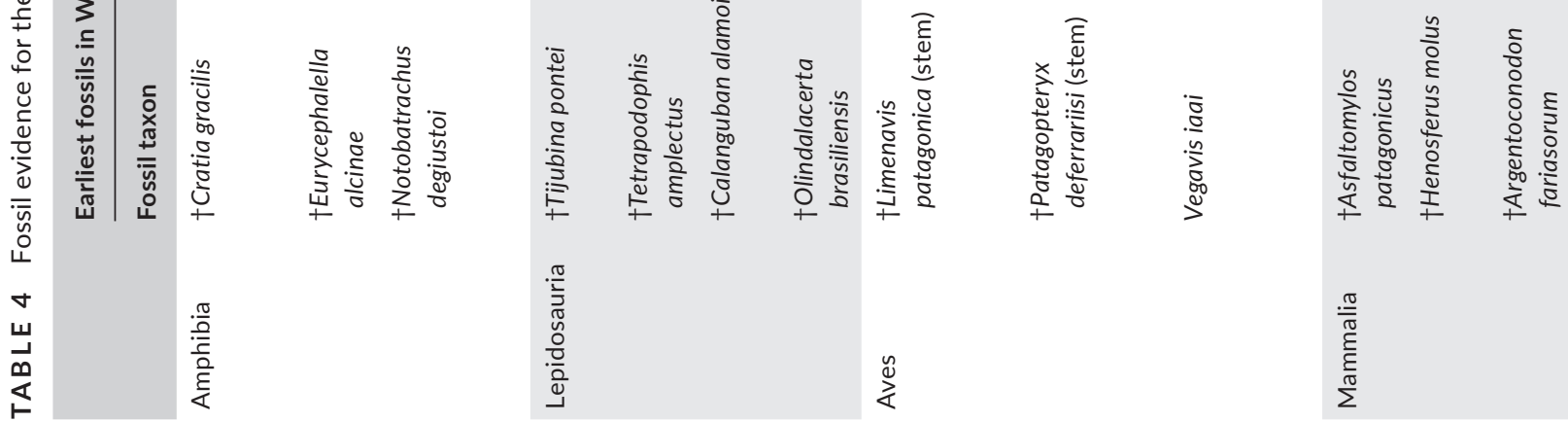

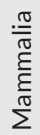


does not estimate ancestral states, hence diversification rates in each region are derived from current species distributions, assuming that evolutionary lineages persisted in their current location through time, which could introduce some biases in the estimation of regional diversification curves (Figure 3). More complex time-episodic or continuously varying diversification models would be required to infer regional increases/decreases in tetrapod diversification over time (Condamine, Rolland, \& Morlon, 2013; Stadler, 2011).

In contrast to Amphibia, our results for birds, lepidosaurs and mammals reveal that the Neotropics acted more as a diversity sink from their origin and until the Pliocene (the Miocene for birds). Diversification rates were lower in the Neotropics, and turnover higher, than in other areas during this period following BiSSE.td (they were inferred equivalent across regions in BAMM). Afterwards, extinction decreased relative to speciation, resulting in a Neotropical diversification upshift in comparison to other areas, suggesting that the Neotropics became a source of diversity only in the recent past (Figures 2 and 3). Previous global studies have, in some cases, produced discrepant results. For example, latitudinal differences in diversification rates were not detected for birds using the same bird data set as our study (Jetz et al., 2012; Rabosky, Title, \& Huang, 2015). These studies, however, are not directly comparable with ours, because the inferences of Jetz et al. (2012) are based on the study of recent speciation events, whereas our results are estimated across the entire history of birds, and Rabosky et al. (2015) focused on the New World only.

The BiSSE.td and BAMM results might also suggest that diversification rates of birds, lepidosaurs and mammals increased through time in the Neotropics and elsewhere regions, especially during the Neogene (they might have decreased elsewhere for lepidosaurs based on BiSSE.td; Figures 2 and 3). Previous studies on birds (Claramunt \& Cracraft, 2015) and mammals (Rolland et al., 2014) also support a global increase in net diversification towards the present. However, as commented before, further analyses would be required to confirm this hypothesis.

Biogeographical dynamics also changed for lepidosaurs and mammals after the Pliocene and for birds after the Miocene (Figure 2). Lepidosaurs are most likely to have originated outside the Neotropics. The earliest fossils assigned to crown lepidosaurs come from the early Triassic of Europe (e.g., Diphydontosarus sp.; c. $240 \mathrm{Ma}$ ). Lepidosaurs colonized Western Gondwana during the Early Cretaceous (c. $110 \mathrm{Ma}$ ), as supported by fossil evidence and our reconstructions (Figure 4; Table 4; Supporting Information Appendix S1). Hence, they could have migrated into the Neotropics through still adjacent Gondwana landmasses. Our analyses also suggest that dispersal rates were low and equivalent between areas $\left(d_{\mathrm{NE}}=d_{\mathrm{EN}}\right)$ for lepidosaurs through time. This result contrasts with a previous study on this group pointing towards higher dispersal rates into the tropics (including the whole equatorial belt; Pyron, 2014b), which might be explained by the different definition of areas in our studies and our use of time-variable models.

For birds, there is still uncertainty around their time of origin and timing of Neotropical colonization, with substantial differences between published divergence time estimates. The issue comes in part from the uncertainty in the assignment of some early bird fossils to crown or stem groups (e.g., Aves versus Avialae). Nonetheless, there is a general consensus that modern birds originated in the Cretaceous (Claramunt \& Cracraft, 2015; Jetz et al., 2012; Ksepka \& Phillips, 2015; Mayr, 2014). Stem fossil representatives (e.g., Enantiornithes) appeared widespread in South America and other regions during the Early Cretaceous (Table 3). Fossils of modern birds (Neornithes) are also widespread in the Late Cretaceous (c. 70 Ma; Mayr, 2014). This fossil evidence conflicts with phylogenetically based biogeographical estimations regarding the reconstruction of the ancestors and the timing of Neotropical colonization: Claramunt and Cracraft (2015) hypothesized that Neornithes originated in Western Gondwana during the Late Cretaceous (c. $95 \mathrm{Ma}$ ) and later spread to the rest of the world. Meanwhile, our BiSSE and DEC results point towards an Early Cretaceous origin for birds elsewhere (c. $120 \mathrm{Ma}$ ), followed by a Late Cretaceous-early Cenozoic entry to the Neotropics (Figure 4). In both cases, biogeographical reconstructions based on phylogenetic data fail to identify widespread Neornithes ancestors in the Cretaceous, which could be attributed to sampling biases, model violations or elevated rates of extinction (Sanmartín \& Meseguer, 2016).

For mammals, the results of phylogenetic investigations also differ regarding the distribution of the ancestors of current diversity. Previous studies suggest that crown mammal lineages were widespread (Springer, Meredith, Janecka, \& Murphy, 2011). Our BiSSE ancestral reconstruction estimates a Western Gondwana origin in the Middle-Late Jurassic for these ancestors. In contrast, our DEC reconstruction and the fossil record point towards an origin of mammals outside the Neotropics during this period (Figure 4). The oldest crown mammal fossils come from the Late Jurassic of China (e.g., Juramaia sinensis; c. 160 Ma; Table 4; Supporting Information Appendix S1). Additionally, the fossil records of species-rich living mammal orders, such as rodents, bats, primates, cetartiodactyls, perissodactyls, lagomorphs or carnivorans, also point to an origin outside the Neotropics. The only mammalian groups for which a Neotropical origin is supported based on fossils are didelphimorphian marsupials, xenarthrans and sirenians (Antoine, SalasGismondi, Pujos, Ganerød, \& Marivaux, 2017), altogether suggesting that mammals probably originated outside the Neotropics.

Dispersal rates of mammals through time are higher out of the Neotropics than into the Neotropics $\left(d_{\mathrm{NE}}>d_{\mathrm{EN}}\right)$, supporting the Neotropics as a source of mammalian diversity (Marshall \& De Muizon, 1988). Dispersal out of the Neotropics increased 3.5 Ma (Figure 2), coincident with the appearance of land corridors across Mesoamerica and the Great American Biotic Interchange (Montes et al., 2015). Higher dispersal rates out of the Neotropics for mammals contrast with fossil evidence showing a major contribution of elsewhere incomers to Neotropical mammalian assemblages (Antoine et al., 2017). This discrepancy might be explained by long-distance sweepstake dispersal events from Africa in Palaeogene times (e.g., platyrrhine primates and caviomorph rodents; Antoine et al., 2012) and the controversial BiSSE reconstruction of a Neotropical mammal ancestor.

In the present study, we investigated differences in diversification between the Neotropics and the rest of the world, whereas 
similar studies in the literature have generally focused on the entire equatorial region (including the Neotropics, the Afrotropics and tropical Asia) or on comparisons within the New World. Hence, the results of our study and previous ones are not directly comparable. But if the diversification dynamics inferred for the whole equatorial belt in some way parallel Neotropical dynamics, then our study suggests that the lower turnover rates and higher diversification in the tropics estimated in previous studies of mammals (Rolland et al., 2014; Weir \& Schluter, 2007), lepidosaurs (Pyron, 2014b) and birds (Cardillo et al., 2005; Pulido-Santacruz \& Weir, 2016; Ricklefs, 2006; Weir \& Schluter, 2007) using time-constant models might apply only to the recent past and not to the entire evolutionary history of these lineages. This is in agreement with a previous study considering continuous time variation in SSE models (Rolland et al., 2014), which also detected high turnover rates in the equator during the early mammal history. The use of time-constant models in previous studies has probably hindered this pattern.

The ensuing question is thus, what explains the global change in diversification dynamics detected during the Pliocene for mammals and lepidosaurs and the Miocene for birds? Time alone cannot explain why the Neotropical region was a sink of diversity during the early history of these groups and later turned into a source. The Neotropics have been occupied by current tetrapods at least since the Early-Late Cretaceous (Figure 4; Hoorn et al., 2010), suggesting that these lineages had sufficient time to diversify in the region. An alternative explanation could be related to climate. Tropical-like environments might have extended on Earth until the early Cenozoic (Ziegler et al., 2003), when a global cooling trend intensified, culminating with the Pleistocene glaciations (Zachos et al., 2008). Climate change extirpated tropical conditions and corresponding biota at higher latitudes (Meseguer \& Condamine, 2020). It also promoted increases in aridification in tropical regions of Africa (Senut, Pickford, \& Ségalen, 2009). In comparison, South America remained relatively stable and might not only have preserved diversity, but also could have exported diversity to other regions as climate progressively deteriorated and diversification decreased elsewhere. This could be the case for lepidosaurs, for which we detected increases in extinction elsewhere after the Pliocene (Figure 2). For birds and mammals, we detected a punctual decrease in speciation and extinction rates in all areas after 15 and 3.5 Ma, respectively, but the decrease in extinction was stronger in the Neotropics. As a result, Neotropical diversification outpaced diversification elsewhere. This suggest that, in addition to climate, other factors could have contributed to reduce extinction risk in the region. For example, the rise of the Andes, which intensified c. 12-4.5 Ma, has been suggested to affect regional climate (Hoorn et al., 2010) and to increase environmental heterogeneity, creating biotic corridors for mountain dispersal in addition to dispersal barriers (Defler, 2019; Silva et al., 2019; Weir, 2006), ultimately resulting in new opportunities for diversification. But besides general explanations, lineage-specific attributes not evaluated in the present study must be also considered to explain this pattern. In fact, our HiSSE analyses indicate that the geographical distribution of lineages might not be the only cause influencing diversification in our data set, and other characters not considered here might also have played a role (Table 2). This is evidenced when applying trait-independent methods to investigate diversification; rate heterogeneity across tetrapod phylogenies was detected, but rate shifts do not always coincide with the acquisition of a Neotropical distribution (Figures S13-S16). Overall, our results suggest that the Neotropics were a prolonged source of world diversity for amphibians and only a recent source for mammals, lepidosaurs and birds, with a confluence of factors explaining differences in diversification between regions and through time (Donoghue \& Sanderson, 2015).

\section{ACKNOWLEDGMENTS}

The authors are grateful to Nicolas Chazot for providing the scripts to perform the biogeographical lineage-through-time plots. This work was funded by an "Investissements d'Avenir" grant managed by the Agence Nationale de la Recherche (CEBA, ref. ANR-10-LABX-25-01) and by the ANR GAARAnti project (ANR-17-CE31-0009). Analyses were done in the Montpellier Bioinformatics Biodiversity cluster-computing platform of the Labex CeMEB (ANR-10-LABX-0004). This is publication ISEM 2020-105 of the Institut des Sciences de l'Evolution de Montpellier (ISEM).

\section{AUTHOR CONTRIBUTIONS}

A.S.M., F.D. and F.L.C. designed the study; A.S.M. and F.L.C. analysed the data; F.L.C., A.S.M. and P.-O.A. gathered the fossil data; A.S.M., F.L.C., F.D., P.-O.A. and A.F. interpreted the results. A.S.M. wrote the manuscript with contributions from F.L.C. and all the other authors.

\section{DATA AVAILABILITY STATEMENT}

Distributional data are provided in FigShare https://doi. org/10.6084/m9.figshare.12090891. All the other data used in this manuscript are presented in the manuscript and its Supporting information.

\section{ORCID}

Andrea S. Meseguer iD https://orcid.org/0000-0003-0743-404X Fabien L. Condamine iD https://orcid.org/0000-0003-1673-9910

\section{REFERENCES}

Alves, D. M. C. C., Diniz-Filho, J. A. F., \& Villalobos, F. (2017). Geographical diversification and the effect of model and data inadequacies: The bat diversity gradient as a case study. Biological Journal of the Linnean Society, 121, 894-906. https://doi.org/10.1093/biolinnean/blx030

AmphibiaWeb. (2019). AmphibiaWeb homepage. Retrieved from https:// amphibiaweb.org

Antoine, P.-O., Marivaux, L., Croft, D. A., Billet, G., Ganerød, M., Jaramillo, C., ... Gismondi, R. S. (2012). Middle Eocene rodents from Peruvian Amazonia reveal the pattern and timing of caviomorph origins and biogeography. Proceedings of the Royal Society B: Biological Sciences, 279, 1319-1326. https://doi.org/10.1098/rspb.2011.1732

Antoine, P.-O., Salas-Gismondi, R., Pujos, F., Ganerød, M., \& Marivaux, L. (2017). Western Amazonia as a hotspot of Mammalian biodiversity 
throughout the Cenozoic. Journal of Mammalian Evolution, 24, 5-17. https://doi.org/10.1007/s10914-016-9333-1

Antonelli, A., \& Sanmartín, I. (2011). Why are there so many plant species in the Neotropics? Taxon, 60, 403-414. https://doi.org/10.1002/ $\operatorname{tax} .602010$

Antonelli, A., Zizka, A., Carvalho, F. A., Scharn, R., Bacon, C. D., Silvestro, D., \& Condamine, F. L. (2018). Amazonia is the primary source of Neotropical biodiversity. Proceedings of the National Academy of Sciences USA, 115, 6034-6039. https://doi.org/10.1073/pnas.1713819115

Antonelli, A., Zizka, A., Silvestro, D., Scharn, R., Cascales-Miñana, B., \& Bacon, C. D. (2015). An engine for global plant diversity: highest evolutionary turnover and emigration in the American tropics. Frontiers in Genetics, 6, 130. https://doi.org/10.3389/fgene.2015.00130.

Beaulieu, J. M., \& O'Meara, B. C. (2016). Detecting hidden diversification shifts in models of trait-dependent speciation and extinction. Systematic Biology, 65, 583-601. https://doi.org/10.1093/sysbio/syw022

Becerra, J. X., \& Venable, D. L. (2008). Sources and sinks of diversification and conservation priorities for the Mexican tropical dry forest. PLoS ONE, 3, e3436. https://doi.org/10.1371/journal.pone.0003436

Bininda-Emonds, O. R. P., Cardillo, M., Jones, K. E., MacPhee, R. D. E., Beck, R. M. D., Grenyer, R., ... Purvis, A. (2007). The delayed rise of present-day mammals. Nature, 446(7135), 507-512. https://doi. org/10.1038/nature05634

Burgin, C. J., Colella, J. P., Kahn, P. L., \& Upham, N. S. (2018). How many species of mammals are there? Journal of Mammalogy, 99(1), 1-14.

Cardillo, M., Orme, C. D. L., \& Owens, I. P. F. (2005). Testing for latitudinal bias in diversification rates: An example using new world birds. Ecology, 86, 2278-2287. https://doi.org/10.1890/05-0112

Chazot, N., Willmott, K. R., Condamine, F. L., De-Silva, D. L., Freitas, A. V. L., Lamas, G., ... Elias, M. (2016). Into the Andes: Multiple independent colonizations drive montane diversity in the Neotropical clearwing butterflies Godyridina. Molecular Ecology, 25, 5765-5784. https://doi.org/10.1111/mec.13773

Claramunt, S., \& Cracraft, J. (2015). Evolutionary ecology: A new time tree reveals Earth history's imprint on the evolution of modern birds. Science Advances, 1, e1501005.

Condamine, F. L., Rolland, J., \& Morlon, H. (2013). Macroevolutionary perspectives to environmental change. Ecology Letters, 16, 72-85. https://doi.org/10.1111/ele.12062

Davis, M. P., Midford, P. E., \& Maddison, W. (2013). Exploring power and parameter estimation of the BiSSE method for analyzing species diversification. BMC Evolutionary Biology, 13, 38. https://doi. org/10.1186/1471-2148-13-38

Defler, T. (2019). The genesis of the modern Amazon River Basin and Andean uplift and their roles in mammalian diversification. In N. H. Landman \& P. J. Harries (Eds.), History of terrestrial mammals in South America (pp. 235-257). Cham: Springer.

Del Hoyo, J., Elliott, A., Sargatal, J., Christie, D. A., \& de Juana, E. (2018). Handbook of the birds of the world alive. Barcelona: Lynx Edicions.

Donoghue, M. J., \& Sanderson, M. J. (2015). Confluence, synnovation, and depauperons in plant diversification. New Phytologist, 207, 14698137. https://doi.org/10.1111/nph.13367

Feng, Y.-J., Blackburn, D. C., Liang, D., Hillis, D. M., Wake, D. B., Cannatella, D. C., \& Zhang, P. (2017). Phylogenomics reveals rapid, simultaneous diversification of three major clades of Gondwanan frogs at the Cretaceous-Paleogene boundary. Proceedings of the National Academy of Sciences USA, 114, E5864-E5870. https://doi. org/10.1073/pnas.1704632114

FitzJohn, R. G. (2012). Diversitree: Comparative phylogenetic analyses of diversification in R. Methods in Ecology and Evolution, 3, 1084-1092.

Fjeldså, J., Bowie, R. C. K., \& Rahbek, C. (2012). The role of mountain ranges in the diversification of birds. Annual Review of Ecology, Evolution, and Systematics, 43, 249-265. https://doi.org/10.1146/ annurev-ecolsys-102710-145113

Gentry, A. H. (1982). Neotropical floristic diversity: Phytogeographical connections between Central and South America, Pleistocene climatic fluctuations, or an accident of the Andean orogeny? Annals Missouri Botanical Garden, 69, 557-593. https://doi. org/10.2307/2399084

Goldberg, E. E., Lancaster, L. T., \& Ree, R. H. (2011). Phylogenetic inference of reciprocal effects between geographic range evolution and diversification. Systematic Biology, 60, 451-465. https://doi. org/10.1093/sysbio/syr046

Hillebrand, H. (2004). On the generality of the latitudinal diversity gradient. The American Naturalist, 163, 192-211. https://doi. org/10.1086/381004

Hoorn, C., Wesselingh, F. P., Ter Steege, H., Bermudez, M. A., Mora, A., Sevink, J., ... Antonelli, A. (2010). Amazonia through time: Andean uplift, climate change, landscape evolution, and biodiversity. Science, 330, 927-931. https://doi.org/10.1126/science.1194585

Igea, J., \& Tanentzap, A. J. (2019). Multiple macroevolutionary routes to becoming a biodiversity hotspot. Science Advances, 5, eaau8067. https://doi.org/10.1126/sciadv.aau8067

Iturralde-Vinent, M. A., \& MacPhee, R. D. E. (1999). Paleogeography of the Caribbean region: Implications for Cenozoic biogeography. Bulletin of the American Museum of Natural History, 238, 1-95.

IUCN. (2019). The IUCN red list of threatened species. Version 2019. Retrieved from https://www.iucnredlist.org

Jablonski, D., Roy, K., \& Valentine, J. W. (2006). Out of the tropics: Evolutionary dynamics of the latitudinal diversity gradient. Science, 314, 102-106. https://doi.org/10.1126/science.1130880

Jansson, R., \& Davies, T. J. (2008). Global variation in diversification rates of flowering plants: Energy vs. climate change. Ecology Letters, 11, 173-183. https://doi.org/10.1111/j.1461-0248.2007.01138.x

Jansson, R., Rodríguez-Castañeda, G., \& Harding, L. E. (2013). What can multiple phylogenies say about the latitudinal diversity gradient? A new look at the tropical conservatism, out of the tropics, and diversification rate hypotheses. Evolution, 67, 1741-1755. https://doi. org/10.1111/evo.12089

Jenkins, C. N., Pimm, S. L., \& Joppa, L. N. (2013). Global patterns of terrestrial vertebrate diversity and conservation. Proceedings of the National Academy of Sciences of the USA, 110, E2602-E2610. https:// doi.org/10.1073/pnas.1302251110

Jetz, W., Thomas, G. H., Joy, J. B., Hartmann, K., \& Mooers, A. O. (2012). The global diversity of birds in space and time. Nature, 491, 444-448. https://doi.org/10.1038/nature11631

Ksepka, D. T., \& Phillips, M. J. (2015). Avian diversification patterns across the K-Pg boundary: Influence of calibrations, datasets, and model misspecification. Annals of the Missouri Botanical Garden, 100, 300-328.

Kuhn, T. S., Mooers, A., \& Thomas, G. H. (2011). A simple polytomy resolver for dated phylogenies. Methods in Ecology and Evolution, 2, 427-436. https://doi.org/10.1111/j.2041-210X.2011.00103.x

Lagomarsino, L. P., Condamine, F. L., Antonelli, A., Mulch, A., \& Davis, C. C. (2016). The abiotic and biotic drivers of rapid diversification in Andean bellflowers (Campanulaceae). New Phytologist, 210, 14301442. https://doi.org/10.1111/nph.13920

Longrich, N. R., Bhullar, B.-A. S., \& Gauthier, J. A. (2012). Mass extinction of lizards and snakes at the Cretaceous-Paleogene boundary. Proceedings of the National Academy of Sciences USA, 109, 2139621401. https://doi.org/10.1073/pnas.1211526110

Maddison, W. P., Midford, P. E., \& Otto, S. P. (2007). Estimating a binary character's effect on speciation and extinction. Systematic Biology, 56, 701-710. https://doi.org/10.1080/10635150701607033

Marshall, L. G., \& De Muizon, C. (1988). The dawn of the age of mammals in South America. National Geographic Research, 4, 23-55.

Mayr, G. (2014). The origins of crown group birds: Molecules and fossils. Palaeontology, 57, 231-242. https://doi.org/10.1111/pala.12103

Meseguer, A. S., \& Condamine, F. L. (2020). Ancient tropical extinctions at high latitudes contributed to the latitudinal diversity gradient. Evolution. https://doi.org/10.1111/evo.13967 
Meseguer, A. S., Lobo, J. M., Cornuault, J., Beerling, D., Ruhfel, B. R., Davis, C. C., ... Sanmartín, I. (2018). Reconstructing deep-time paleoclimate legacies in the clusioid Malpighiales unveils their role in the evolution and extinction of the boreotropical flora. Global Ecology and Biogeography, 27, 616-628.

Mittermeier, R. A., Turner, W. R., Larsen, F. W., Brooks, T. M., \& Gascon, C. (2011). Global biodiversity conservation: The critical role of hotspots. In F. E. Zachos \& J. C. Habel (Ed.), Biodiversity hotspots (pp. 3-22). Berlin, Heidelberg, Germany: Springer.

Montes, C., Cardona, A., Jaramillo, C., Pardo, A., Silva, J. C., Valencia, V., ... Niño, H. (2015). Middle Miocene closure of the Central American Seaway. Science, 348, 226-229.

Neotropical Birds (2019). The cornell lab of ornithology. Retrieved from https://birdsoftheworld.org/bow/home

Olson, D. M., Dinerstein, E., Wikramanayake, E. D., Burgess, N. D., Powell, G. V. N., Underwood, E. C., ... Kassem, K. R. (2001). Terrestrial ecoregions of the world: A new map of life on Earth. BioScience, 51, 933. https://doi.org/10.1641/0006-3568(2001)051[0933:TEOTW A]2.0.CO;2

Pulido-Santacruz, P., \& Weir, J. T. (2016). Extinction as a driver of avian latitudinal diversity gradients. Evolution, 70, 860-872. https://doi. org/10.1111/evo.12899

Pyron, R. A. (2014a). Biogeographic analysis reveals ancient continental vicariance and recent oceanic dispersal in amphibians. Systematic Biology, 63, 779-797. https://doi.org/10.1093/sysbio/syu042

Pyron, R. A. (2014b). Temperate extinction in squamate reptiles and the roots of latitudinal diversity gradients. Global Ecology and Biogeography, 23, 1126-1134. https://doi.org/10.1111/geb.12196

Pyron, R. A., \& Wiens, J. J. (2013). Large-scale phylogenetic analyses reveal the causes of high tropical amphibian diversity. Proceedings of the Royal Society B: Biological Sciences, 280(1770), 20131622.

Rabosky, D. L., \& Goldberg, E. E. (2015). Model inadequacy and mistaken inferences of trait-dependent speciation. Systematic Biology, 64, 340-355. https://doi.org/10.1093/sysbio/syu131

Rabosky, D. L., Grundler, M., Anderson, C., Title, P., Shi, J. J., Brown, J. W., ... Larson, J. G. (2014). BAMM tools: An R package for the analysis of evolutionary dynamics on phylogenetic trees. Methods in Ecology and Evolution, 5, 701-707. https://doi.org/10.1111/2041-210X.12199

Rabosky, D. L., Santini, F., Eastman, J., Smith, S. A., Sidlauskas, B., Chang, J., \& Alfaro, M. E. (2013). Rates of speciation and morphological evolution are correlated across the largest vertebrate radiation. Nature Communications, 4, 1958. https://doi.org/10.1038/ncomms2958.

Rabosky, D. L., Title, P. O., \& Huang, H. (2015). Minimal effects of latitude on present-day speciation rates in New World birds. Proceedings of the Royal Society B: Biological Sciences, 282, 20142889. https://doi. org/10.1098/rspb.2014.2889

Ree, R. H., \& Smith, S. A. (2008). Maximum likelihood inference of geographic range evolution by dispersal, local extinction, and cladogenesis. Systematic Biology, 57, 4-14. https://doi.org/10.1080/10635 150701883881

Ricklefs, R. E. (2006). Global variation in the diversification rate of passerine birds. Ecology, 87, 2468-2478. https://doi.org/10.1890/00129658(2006)87[2468:GVITDR]2.0.CO;2

Roelants, K., Gower, D. J., Wilkinson, M., Loader, S. P., Biju, S. D., Guillaume, K., ... Bossuyt, F. (2007). Global patterns of diversification in the history of modern amphibians. Proceedings of the National Academy of Sciences USA, 104, 887-892. https://doi.org/10.1073/ pnas.0608378104

Rolland, J., \& Condamine, F. L. (2019). The contribution of temperature and continental fragmentation to amphibian diversification. Journal of Biogeography, 46, 1857-1873. https://doi.org/10.1111/jbi.13592

Rolland, J., Condamine, F. L., Beeravolu, C. R., Jiguet, F., \& Morlon, H. (2015). Dispersal is a major driver of the latitudinal diversity gradient of Carnivora. Global Ecology and Biogeography, 24, 1059-1071. https://doi.org/10.1111/geb.12354
Rolland, J., Condamine, F. L., Jiguet, F., \& Morlon, H. (2014). Faster speciation and reduced extinction in the tropics contribute to the mammalian latitudinal diversity gradient. PLoS Biology, 12, e1001775. https://doi.org/10.1371/journal.pbio.1001775

Romiguier, J., Ranwez, V., Delsuc, F., Galtier, N., \& Douzery, E. J. P. (2013). Less is more in mammalian phylogenomics: AT-rich genes minimize tree conflicts and unravel the root of placental mammals. Molecular Biology and Evolution, 30, 2134-2144. https://doi.org/10.1093/ molbev/mst116

Sanmartín, I., \& Meseguer, A. S. (2016). Extinction in phylogenetics and biogeography: From timetrees to patterns of biotic assemblage. Frontiers in Genetics, 7, 35. https://doi.org/10.3389/ fgene.2016.00035

Scher, H. D., Whittaker, J. M., Williams, S. E., Latimer, J. C., Kordesch, W. E. C., \& Delaney, M. L. (2015). Onset of Antarctic Circumpolar Current 30 million years ago as Tasmanian Gateway aligned with westerlies. Nature, 523, 580-583. https://doi.org/10.1038/natur e14598

Senut, B., Pickford, M., \& Ségalen, L. (2009). Neogene desertification of Africa. Comptes Rendus Geoscience, 341, 591-602. https://doi. org/10.1016/j.crte.2009.03.008

Silva, S. M., Peterson, A. T., Carneiro, L., Burlamaqui, T. C. T., Ribas, C. C., Sousa-Neves, T., ... Aleixo, A. (2019). A dynamic continental moisture gradient drove Amazonian bird diversification. Science Advances, 5, eaat5752. https://doi.org/10.1126/sciadv.aat5752

Springer, M. S., Meredith, R. W., Janecka, J. E., \& Murphy, W. J. (2011). The historical biogeography of Mammalia. Philosophical Transactions of the Royal Society B: Biological Sciences, 366, 2478-2502. https:// doi.org/10.1098/rstb.2011.0023

Stadler, T. (2011). Inferring speciation and extinction processes from extant species data. Proceedings of the National Academy of Sciences USA, 108, 16145-16146. https://doi.org/10.1073/pnas.1113242108

Stebbins, G. L. (1974). Flowering plants: Evolution above the species level. Cambridge, MA: Harvard University Press.

Stephens, P. R., \& Wiens, J. J. (2003). Explaining species richness from continents to communities: The time-for-speciation effect in emydid turtles. The American Naturalist, 161, 112-128. https://doi. org/10.1086/345091

Töpel, M., Zizka, A., Calió, M. F., Scharn, R., Silvestro, D., \& Antonelli, A. (2017). SpeciesGeoCoder: Fast categorization of species occurrences for analyses of biodiversity, biogeography, ecology, and evolution. Systematic Biology, 66, 145-151.

Uetz, P., Freed, P., \& Hošek, J. (eds.) (2018). The reptile database. Retrieved from http://www.reptile-database.org

Weir, J. T. (2006). Divergent timing and patterns of species accumulation in lowland and highland neotropical birds. Evolution, 60, 842-855. https://doi.org/10.1111/j.0014-3820.2006.tb01161.x

Weir, J. T., \& Schluter, D. (2007). The latitudinal gradient in recent speciation and extinction rates of birds and mammals. Science, 315, 15741576. https://doi.org/10.1126/science.1135590

Wiens, J., \& Donoghue, M. (2004). Historical biogeography, ecology and species richness. Trends in Ecology and Evolution, 19, 639-644. https://doi.org/10.1016/j.tree.2004.09.011

Winger, B. M., Barker, F. K., \& Ree, R. H. (2014). Temperate origins of long-distance seasonal migration in New World songbirds. Proceedings of the National Academy of Sciences USA, 111, 1211512120. https://doi.org/10.1073/pnas.1405000111

Zachos, J. C., Dickens, G. R., \& Zeebe, R. E. (2008). An early Cenozoic perspective on greenhouse warming and carbon-cycle dynamics. Nature, 451, 279-283. https://doi.org/10.1038/nature06588

Ziegler, A. M., Eshel, G., McAllister Rees, P., Rothfus, T. A., Rowley, D. B., \& Sunderlin, D. (2003). Tracing the tropics across land and sea: Permian to present. Lethaia, 36, 227-254. https://doi.org/10.1080/00241 160310004657 


\section{BIOSKETCHES}

Andrea S. Meseguer is a researcher at the Real Jardín Botánico (CSIC, Spain) interested in macroevolution and the factors and processes generating geographical and diversity patterns.

Fabien L. Condamine is a research scientist at ISEM (CNRS, France). His main research interests include the study of large-scale diversity patterns and the development of parametric methods in biogeography and macroevolution. Members of the project NeotroPhyl, of the Laboratoire of excellence CEBA (Center for the study of biodiversity in Amazonia), are interested in understanding why so many species are present in tropical ecosystems and inferring the drivers of Neotropical diversification using macroevolutionary approaches.

\section{SUPPORTING INFORMATION}

Additional Supporting Information may be found online in the Supporting Information section.

How to cite this article: Meseguer AS, Antoine P-O, Fouquet A, Delsuc F, Condamine FL. The role of the Neotropics as a source of world tetrapod biodiversity. Global Ecol Biogeogr. 2020;29:1565-1578. https://doi.org/10.1111/geb.13141 